describes in detail three cases with the post-mortem appearances. But in this communication every case described followed chloroform administration. My case shortly is as follows :-

A well-developed, bright-looking, and apparently healthy girl, aged six years, was admitted to hospital for deafness owing to the presence of adenoids. On the morning of Nov. 13th, 1907, after having been prepared in the usual manner, ethyl chloride was administered and the adenoids were removed, the operation, including administration of the anæsthetic, taking about a minute; the child recovered completely and was then placed in bed. Towards evening she vomited twice but slept well during the night and no vomiting occurred. On the next day she complained of severe headache and of nausea. She retiched a good deal during the day and vomited a few minutes after taking any food, so she was given some bismuth mixture in the evening. During the night she slept fairly well but vomited once, whereupon the medicine was repeated. On the 15th she complained of violent frontal headache and vomited immediately after taking anything by the mouth. Towards evening the pulse became rapid and small and the child felt very cold, so hot bottles were placed in the bed. During the night she slept fairly well but vomited twice after drinking a little milk. On the 16th the aspect of the child had completely altered during the past two days. She now lay in bed with her knees drawn up, taking no notice of anything, but answering when spuken to and complaining of great frontal headache and of pain in the abdomen; her eyes were very sunken and her face was somewhat pale, worn-looking, and drawn; in fact, her aspect resembled that of a patient who had suffered from some severe illness, such as typhoid fever, for some weeks. The child was very cold, her tongue was coated and dry, her pulse was quite feeble, very rapid and irregular; in fact, she was very ill. She had been given an enema simplex and was receiving bismuth mixture every four hours ; she retained no food, vomiting immediately anything that she swallowed. It had been thought up to now that probably she was developing some intercurrent disease. However, her aspect and the continual vomiting made me suspect acid intoxication, so a sample of urine was obtained, which Dr. T. Houston kindly tested and found it to contain diacetic acid, thus confirming the diagnosis. She was now given rectal iniections of 1 drachm of bicarbonate of sodium in 2 ounces of warm water every four hours, and during the night, also bismuth mixture and a little peptonised milk and water, this and the mixture containing 10 grains of bicarbonate of sodium to the dose, but both were vomited immediately after being drunk and so were stopped. On the 17th the child was distinctly better, the worn aspect had vanished, and the eyes did not appear so sunken. She looked brighter and felt easier and had no headache or pain in the abdomen; the pulse was still rapid but regular and better in quality. During the early part of the night she had vomited twice, but not since she was not given any food by the mouth, receiving rectal feeds of 4 ounces of peptonised milk containing 20 grains of bicarbonate of sodium every four hours. After 6 P.M. she was given peptonised milk in half-ounce quantities by the mouth which she retained. This was therefore gradually increased in quantity as no vomiting occurred, the rectal feeds being continued during the night. On the 18th there was no vomiting, the child looked brighter and better, and did not complain of pain anywhere. The pulse was slower, steadier, and improving in quality ; the tongue was becoming clean. The rectal feeding was now discontinued, the patient being given 5 ounces of peptonised milk every two hours by the mouth; in the evening this was replaced by ordinary milk. On the 19 th the child was improving rapidly; there was no vomiting and the pulse was normal. The urine tested on this day was found to be free from diacetic acid. The subsequent history was uneventful. The temperature during the illness never rose above $99 \cdot 8^{\circ} \mathrm{F}$., nor fell below normal.

This, then, appears to be a case of acid intoxication following ethyl-chloride anæsthesia, which when recognised and treated appropriately had a fortunate termination, though on the third day after the operation the little patient was so ill that this, coupled with the fatal terminations in the recorded cases following chloroform administration, made one give a very gloomy prognosis. In view of the able manner in which M'r. Campbell has described the whole subject of chloroform poisoning I will refer the reader to his paper and content myself by quoting as an explanation why acid intoxication should follow ethyl-chloride administration the suggestion made by Dr. V. G. L. Fielden, the anæsthetist to the hospital, that the halogen group occurs both in chloroform and in ethyl chloride. In conclusion, I have to thank Miss 'Tate, the matron, for many of the notes on this case. Belfast.

\section{A NOTE ON THE DEVELOPMENT OF SECONDARY NODULES IN SUTURE SCARS AFTER OPERATIONS FOR THE REMOVAL OF CANCER.}

BY C. W. MANSELL MOULLIN, F.R.C.S. ENG., SENIOR SURGEON AND LECTURER ON SURGERY AT THE LONDON HOSPITAL.

In The Lancer of Nov. 9th, 1907, Mr. Charles Ryall called the attention of the profession to the very grave risk of cancer infection taking place during the performance of operations for the removal of cancerous growths, and instanced many cases in which it seemed to be obvious that such infection had occurred. One of the examples brought forward was the well-known frequent recurrence of the disease in the suture cicatrices atter operations upon the breast, and several striking instances were mentioned in which infection had taken place around a laparotomy wound even when the operation had been merely of an exploratory character. A case that has been recently under my care illustrates this point well, but at the same time suggests that the mode of transference of the cancer infection is not of quite such a simple character as is usually believed. The sutures must bear a part of the blame, perhaps the greater part ; but there is something more than the mere conveyance of a cancer cell from one spot to another by the needle or suture employed.

The patient, a man 48 years of age, was sent to me with the history that he had suffered from chronic gastric ulcer for the last 18 years, and that lately, in spite of medical treatment, the attacks of pain and vomiting had become more frequent. Cancer had supervened upon the old ulcer, as it so often does, and at the operation a tight stricture of the pylorus was found with some disseminated nodules scattered over the serous surface of the stomach. Posterior transmesocolic gastro-enterostomy was performed and the patient made an uneventful recovery. Six months later I saw him again. He was much better so far as pain was concerned and was considerably stouter, but there was a double row of cancer nodules on either side of the laparotomy wound. Two sets of sutures had been inserted: one, of stout catgut, interrupted, passing through all the layers of the abdominal wall except the skin ; the other, of finer catgut, continuous, through the skin only. Practically all the suture points of the former series were infected; none of the latter. It was evident that cancer cells from the peritoneal cavity had invaded the wall wherever the parietal peritoneum had been pierced by a suture. The sutures had not carried the cancer germs in, for they had never been near the growth; but either by perforating the serous layer or by acting as irritants they had helped the development of the invading germs to such an extent that each point had become a cancer nodule. The immediate source of infection was in all probability the nodules noted on the serous coat of the stomach, which were constantly rubbing against the anterior abdominal wall. The line of the laparotomy incision itself seemed to be intact between the two rows of nodules.

The same explanation, it seems to me, is the more rational one in those cases in which cancer recurs at the suture points after operations for mammary carcinoma. It is not that the cancer germs are carried in by the needle or suture mechanicaliy at the time of the operation and left to grow in the puncture made, but that they are more widely dis. tributed in the surrounding tissue interstices than is apparent at the time, and only develop, or perhaps develop first, at those points where the resistance of the tissues is lowered by the presence of an irritant such as a suture.

That healthy tissues do possess some power of resistance to the growth of invading cancer germs is obvious. The dis tribution of cancer germs from a primary focus must begin at a very early date, but it is a long time before secondary 
growths make their appearance, and early removal of the primary one often prevents their development entirely. Moreover, though surgeons not uncommonly become infected in the course of operations by pyogenic organisms and by the organisms of tubercle and syphilis, and though they must have run the risk many thousand times in the course of operations upon patients suffering from cancer, I am not aware of any single instance in which they bave become infected. All the instances in which transplanted cancer germs have succeeded in growing have been cases in which the patients were suffering from cancer already, in whom it may be presumed the power of resistance had been already overcome.

One of the cancer problems is to discover in what this power of resistance may consist. It exists at first apparently in all alike. It must be present and well developed for some considerable time in the tissues around a cancerous growth, but it fails at last, and it fails much more quickly if there is some additional irritant present, such as a suture.

Wimpole-street, $\mathrm{W}$.

\section{TWO CASES OF URETERO-PYELOPLASTY}

\section{By ARTHUR H. BURGESS, F.R.C.S. ENG., M.B.} M.Sc. VIOT.

HONORARY ASSISTANT SURGKON TO THE MANCHESTER ROYAL INFIRMARY AND MANCHESTER CANCER HOSPITAL; LECTURER IN SURGERY, UNIVERSITY OF MANCHESTER.

THE operation of uretero-pyeloplasty is one which seeks to overcome a constriction at the junction of the renal pelvis and ureter by a procedure analogous to the better known "pyloroplasty"-viz., longitudinal incision through the stricture, followed by transverse suture of the wound. It is indicated in cases of distension of the renal pelvis from stricture at or about the uretero-pelvic junction, provided sufficient healtby renal substance yet remains to justify conservatism. Constriction at this situation may arise from trauma, from the contraction of an ulcer such as may result from the pressure of an impacted calculus, from the contraction subsequent to peri-ureteric or peri-nephritic inflammation, and it is also one of the two less rare sites of congenital stricture, the other being at the entrance of the ureter into the bladder. I regard, for reasons shortly to be stated, the two cases I am now recording to be instances of congenital stricture, leading in the one case to hydro nephrosis, in the other to pyonephrosis.

UASE 1--A female, aged 32 years, was sent to me at the Royal Infirmary with a swelling in the right side of the abdomen. For some months past she had complained of dull aching pains in the right loin, coming on at intervals of about ten days, and one month ago she accidentally discovered the swellng, which she stated had not appreciably altered in size since. She had never noticed anything unusual in the quantity or quality of her urine. The swelling was of about the size of a cocoanut, distinctly fluctuant, freely moveable in any direction, and easily replaceable into the right loin. The urine was acid, of specific gravity 1022, and contained no abnormal constituent. On Feb. 5th 1907, under chloroform, I cystoscoped the bladder and found it quite healthy, nor were there any differences in appearance between the two ureteric orifices. As the kidneys had temporarily stopped secreting under the influence of the anæsthetic the character of the urinary flow from the two orifices could not be compared. A catheter passed easily along the right ureter for a distance of 11 inches, and was left in situ, no urine escaping from it. The patient was then turned over on to her left side and the usual lumbar incision for exposure of the kidney was made. The large cyst was readily exposed and incised, and about 30 ounces of a pale-yellow fluid escaped. The cyst was then separated and brought well up into the wound, when it was found to be the dilated renal pelvis, with the kidney, the calyces of which were comparatively but slightly affected, situated on its outer and posterior aspects. The uretier was readily found by means of the catheter still remaining in it, and which was seen to have passed as far as the junction of the ureter and the distended pelvis, where its further passage had been prevented by a very tight constriction. The ureter was of normal size and there were no signs of any previous peri-nreteritis. A small incision was made on the anterior surface of the pelvis, half an inch above the uretero-pelvic junction, and the constriction was examined from above. With some difficulty a fine wire fprobe was passed through it from above and the catheter was withdrawn rom the ureter. The incision was then continued downwards through the stricture and along the long axis of the ureter for a distance of balf an inch. There was no ulceration at the site of the stricture, nor did the mucosa exhibit any scars. This longitndinal wound was then sutured transversely, with two rows of fine catgut, the inner not intentionally incluaing the mucosa. A large rubber drainagetube was then inserted into the pelvis through the original incision into it and the kidney was fixed to the loin as high up as possible. The external wound was closed around the tube. Five days later the tube was removed and on Feb. 20th the external wound was completely healed. I last saw her on Nov. 12th and could feel the kidney, ratker smaller than normal, firmly fixed to the loin. There bad been no recurrence of the swelling and the symptoms had been completely cured.

The absence of any signs of cicatricial contraction or other. cause to account for the constriction in this case, together with its exact limitation to the uretero-pelvic junction, incline me tu regard it as of congenital nature. The absence of hydronephrosis until middle life shows that the constriction was not at first of severe degree. Later the kidney became moveable and consequently no doubt suffered from frequent attacks oi congestion which sufficed to aggravate the constriction to an extent sufficient to lead to pelvic distension.

CASE 2.-A female, aged 21 years, was admitted to the Royal Infirmary on Dec. 17th, 1906, complaining of "pains in the back" and " muddy " nrine. She had been told that her pains commenced at the age of three years, and she herself dia not remember ever being free from them for any length of time. The change in the urine was noticed about three years ago and though slight at first it had steadily become more marked. She had been in hospital several times without material relief. On admission she located her pain to the upper lumbar region of the spine and conld not say that it was ever more marked on one side than on the other. The pain always came on in attacks and usually during the night. The abdomen appeared to be tender and palpation was difficult, but I thought palpation over the left kidney was more painful and gave a feeling of greater resistance than that over the right. The urine was 1020, alkaline, contained albumin, no sugar, with a very thick deposit of pus. A radiogram showed an indefinite shadow in the left kidney region. On Dec. 28th I cystoscoped under anæsthesia and found the appearances of general cystitis. Apart from this the right ureteric orifice was unaltered, but that on the left stood prominently out like a pyramid and its margins were extremely swollen and acutely congested. The discharge from the right ureter was apparently clear while that from the left came irregularly and was very turbid. I at once exposed the left kidney from the loin, separated it from its adhesions to surrounding parts, and drew it well up into the wound. The pelvis and calyces were distended with pus. The kidney was incised along its convex border through a dilated calyx and the pelvis was thoroughly flushed out with saline solution. Three small calculi were found inclosed in the lowest calyx and were removed. The ureter was now exposed and was found to be of normal size, but exactly at the uretero-pelvic junction there was a narrow constriction. A small incision was then made in the anterior wall of the pelvis half an inch above this constriction and its upper aspect was inspected. It was treated as in Case 1 by uretero-pyeloplasty, but before closing the incision in the pelvis and ureter a bougie was passed downwards along the latter into the bladder to insure the absence of other obstruction. The pelvis was drained by a rubber tube passed through the original incision in the kidney substance and the organ was fixed to the lambar wound, a tube being inserted also into the perirenal space below. Shock was rather severe for two days but afterwards the patient steadily progressed. The tubes were retained until Jan. 12th and she left for the convalescent home on the 30th with a small sinus, which finally healed on March 15th. She is now free from the old pains, is in good general health, and the kidney can be felt firmly fixed to the loin and of small size. There is still a small deposit of pus in the urine, which has been acid ever since the operation, but this is gradually diminishing. She can hold her urine for four hours. whereas formerly she passed it as often as every ten minutes.

I think it is probable that in this case also the stricture 